\title{
Sirolimus-Eluting Stent vs. Everolimus-Eluting Stent for Coronary Intervention in Patients on Chronic Hemodialysis
}

Takashi Sakakibara, MD; Hideki Ishii, MD, PhD; Takanobu Toriyama, MD, PhD;

Toru Aoyama, MD, PhD; Hiroshi Takahashi, BSc; Daisuke Kamoi, MD; Yoshihiro Kawamura, MD;

Kazuhiro Kawashima, MD; Kohei Yoneda, MD; Tetsuya Amano MD, PhD;

Miho Tanaka, MD; Daiji Yoshikawa, MD; Mutsuharu Hayashi, MD, PhD;

Tatsuaki Matsubara, MD, PhD; Toyoaki Murohara, MD, PhD

\begin{abstract}
Background: Even in the drug-eluting stent era, adverse cardiac events, including restenosis after percutaneous coronary intervention (PCl), have been more frequently seen in patients on hemodialysis (HD) than in non-HD patients. The objective of this study was to compare the sirolimus-eluting stent (SES) and everolimus-eluting stent (EES) for prevention of adverse cardiac events, including restenosis, in HD patients.

Methods and Results: A total of 100 consecutive patients on HD who underwent PCI were enrolled and randomly assigned to receive SES or EES. Although there was no difference between the 2 groups in baseline patient and lesion characteristics, the angiographic restenosis rate at 8 -month follow-up was $21.2 \%$ in the SES group and $8.7 \%$ in the EES group $(P=0.041)$. Significant differences were also seen in \% diameter stenosis (\%DS), minimal lumen diameter, and late lumen loss at 8-month follow-up $(P=0.0024, P=0.0040$, and $P=0.033$, respectively). During the 1-year follow-up, major adverse cardiac events occurred in 11 (22.0\%) patients in the SES group and in 5 (10.0\%) patients in the EES group $(\mathrm{P}=0.10)$.
\end{abstract}

Conclusions: The use of EES was as safe as that of SES. Moreover, EES significantly prevented restenosis in patients on maintenance HD compared with SES. (Circ J 2012; 76: 351-355)

Key Words: Drug-eluting stent; Hemodialysis; Percutaneous coronary intervention; Restenosis

$\mathbf{C}$ ardiovascular disease is the main reason for the morbidity and mortality in patients requiring hemodialysis (HD). ${ }^{1-3}$ Coronary artery disease is common in patients with HD and percutaneous coronary intervention (PCI) has become an effective therapy for ischemic heart disease in such patients. ${ }^{4,5}$ Although early initial success rates have been high even in patients requiring $\mathrm{HD}$, a relatively higher restenosis rate in the follow-up period has been seen after PCI in patients on HD. ${ }^{6}$ Thus, using drug-eluting stents (DES) has become the most common strategy for preventing restenosis after PCI, but unfortunately, many studies have shown that restenosis after PCI with a sirolimus-eluting stent (SES) is common in patients on HD. ${ }^{7-14}$

Recently, the everolimus-eluting stent (EES) has been widely adopted because it significantly reduces the risk of both adverse cardiac events and restenosis after PCI in many cases. ${ }^{15-19}$
However, because it is unclear whether implantation of the EES has such beneficial effects in patients on HD, the present study evaluated the effects of EES vs. SES on preventing restenosis and adverse cardiac events after PCI in HD patients with coronary artery disease.

\section{Methods}

\section{Study Population}

This prospective, randomized, open-label study consisted of 100 consecutive patients on maintenance HD with stable angina pectoris who underwent PCI for native coronary lesions at Nagoya Kyoritsu Hospital between February 2010 and June 2010. All patients received maintenance HD 3 times a week. They were randomized into 2 groups: those who received SES (Cypher $^{\mathrm{TM}}$, Cordis Corp, Johnson \& Johnson, Miami Lakes,

Received July 27, 2011; revised manuscript received October 17, 2011; accepted October 18, 2011; released online November 30, 2011 Time for primary review: 33 days

Cardiovascular Center, Nagoya Kyoritsu Hospital, Nagoya (T.S., T.T., T. Aoyama, H.T., D.K., Y.K., K.K., K.Y., M.T.); Department of Cardiology, Nagoya University Graduate School of Medicine, Nagoya (T.S., H.I., T. Amano, M.T., D.Y., M.H., T. Murohara); and Department of Internal Medicine, School of Dentistry Aichi-Gakuin University, Nagoya (T. Matsubara), Japan

Mailing address: Hideki Ishii, MD, PhD, Department of Cardiology, Nagoya University Graduate School of Medicine, 65 Tsurumai-cho, Showa-ku, Nagoya 466-8550, Japan. E-mail: hkishii@med.nagoya-u.ac.jp

ISSN-1346-9843 doi:10.1253/circj.CJ-11-0814

All rights are reserved to the Japanese Circulation Society. For permissions, please e-mail: cj@j-circ.or.jp 


\begin{tabular}{|lccc|}
\hline Table 1. Patients' Characteristics & & & \\
Male (\%) & SES group $(\mathbf{n}=\mathbf{5 0})$ & EES group $(\mathbf{n = 5 0 )}$ & P value \\
Age (years) & $38(76.0)$ & $32(64.0)$ & 0.19 \\
Diabetes (\%) & $65 \pm 10$ & $67 \pm 10$ & 0.27 \\
Hypertension (\%) & $37(74.0)$ & $33(66.0)$ & 0.38 \\
Dyslipidemia (\%) & $34(68.0)$ & $36(72.0)$ & 0.66 \\
Current smoker (\%) & $14(28.0)$ & $18(36.0)$ & 0.39 \\
Prior MI (\%) & $11(22.0)$ & $13(26.0)$ & 0.64 \\
Prior stroke (\%) & $4(8.0)$ & $2(4.0)$ & 0.40 \\
Prior peripheral artery disease (\%) & $8(16.0)$ & $5(10.0)$ & 0.37 \\
Duration of HD (years) & $6(12.0)$ & $9(18.0)$ & 0.40 \\
Current smoker (\%) & $6.6 \pm 6.4$ & $6.4 \pm 6.1$ & 0.90 \\
Prior Ml (\%) & $11(22.0)$ & $13(26.0)$ & 0.64 \\
Prior stroke (\%) & $4(8.0)$ & $2(4.0)$ & 0.40 \\
\hline
\end{tabular}

SES, sirolimus-eluting stent; EES, everolimus-eluting stent; MI, myocardial infarction; HD, hemodialysis.

\begin{tabular}{|c|c|c|c|}
\hline & SES group $(n=50)$ & EES group $(n=50)$ & $P$ value \\
\hline No. of lesions & 73 & 74 & \\
\hline Target vessel, $\mathrm{n}(\%)$ & & & 0.85 \\
\hline RCA & 35 (47.9) & $32(43.2)$ & \\
\hline LAD & 17 (23.3) & $19(25.7)$ & \\
\hline LCX & $21(28.8)$ & $23(31.1)$ & \\
\hline ACC/AHA Type, n (\%) & & & 0.48 \\
\hline A & $3(4.1)$ & $3(4.1)$ & \\
\hline B1 & $6(8.2)$ & $5(6.8)$ & \\
\hline B2 & $46(63.0)$ & $39(52.7)$ & \\
\hline C & $19(24.7)$ & $27(36.4)$ & \\
\hline Calcified lesion, n (\%) & $43(58.9)$ & $49(66.2)$ & 0.31 \\
\hline Bifurcation lesion, n (\%) & $13(17.8)$ & $18(24.3)$ & 0.33 \\
\hline Stent diameter (mm) & $3.0 \pm 0.4$ & $3.0 \pm 0.4$ & 0.74 \\
\hline Stent length (mm) & $19.8 \pm 5.9$ & $20.1 \pm 6.3$ & 0.84 \\
\hline Rotational atherectomy, $\mathrm{n}(\%)$ & $3(4.1)$ & $4(5.4)$ & 0.71 \\
\hline Direct stenting (\%) & $11(15.2)$ & $8(10.8)$ & 0.44 \\
\hline
\end{tabular}

RCA, right coronary artery; LAD, left anterior descending artery; LCX, left circumflex artery; ACC, American College of Cardiology; AHA, American Heart Association. Other abbreviations see in Table 1.

FL, USA) and those who received EES (Xience VTM, Abott Vascular, Santa Clara, CA, USA). We enrolled patients with a maximum of 2 de novo coronary artery lesions with length $<30 \mathrm{~mm}$ and vessel diameter $\geq 2.5-\leq 4.0 \mathrm{~mm}$. Tolerance of dual antiplatelet therapy had been checked for all enrolled patients and continued for at least 1 year after PCI.

The primary endpoint was the rate of restenosis at 8-month follow-up, defined as angiographic luminal diameter $>50 \%$ by quantitative coronary angiography (QCA). The secondary endpoints included clinical follow-up data of major adverse cardiac events after the PCI procedure, including all-cause death, nonfatal myocardial infarction, and target lesion revascularization (TLR). Intracoronary $2.5-5 \mathrm{mg}$ doses of isosorbide dinitrate were administered before the initial, final, and follow-up angiograms to achieve maximal vasodilatation. Contrast-filled guide catheters were used as the reference standard in QCA. Matched end-diastolic frames of the angiograms before and after PCI and at 8-month follow-up were analyzed using a contour detection minimum cost algorithm (QCA-CMS Version 3.0, MEDIS, Leiden, The Netherlands). Restenosis was defined as a stent stenosis $>50 \%$ in diameter anywhere within the stent and/or within the 5-mm borders proximal or distal to the stent. Late lumen loss was defined as the difference between minimal lumen diameter (MLD) immediately after PCI and on 8-month follow-up angiography. Types of coronary lesions were characterized according to the American Heart Association/American College of Cardiology (AHA/ACC) classification. ${ }^{20}$ QCA analyses were performed by an experienced technician who was blinded to the assignment to groups.

The study protocol was approved by the hospital's ethics committee, and the physicians obtained written informed consent from each patient.

\section{Statistical Analysis}

Continuous variables are presented as mean \pm standard deviation values. Univariate analysis of differences between the SES and EES groups was performed with the 2-tailed unpaired t-test for continuous outcome variables and by chi-square or Fisher exact tests for discrete outcome variables. Logistic regression analysis models were used to assess univariate and multivariable covariates associated with progression to the 8-month follow-up restenosis. All the prognostic variables with $\mathrm{P}<0.05$ 


\begin{tabular}{|lccc|}
\hline \multicolumn{2}{|l|}{ Table 3. Quantitative Coronary Angiography Data } & & \\
No. of lesions & SES group $(\mathbf{n}=\mathbf{4 6})$ & EES group $(\mathbf{n}=\mathbf{4 7})$ & P value \\
Reference $(\mathrm{mm})$ & 66 & 69 & \\
Lesion length $(\mathrm{mm})$ & $2.69 \pm 0.42$ & $2.69 \pm 0.50$ & 0.98 \\
MLD $(\mathrm{mm})$ & $19.3 \pm 6.0$ & $19.5 \pm 6.7$ & 0.80 \\
Pre & & & \\
Post & $1.01 \pm 0.38$ & $1.05 \pm 0.49$ & 0.56 \\
Follow-up & $2.67 \pm 0.39$ & $2.74 \pm 0.43$ & 0.18 \\
Late loss (mm) & $2.14 \pm 0.74$ & $2.48 \pm 0.59$ & 0.0040 \\
\% diameter stenosis (\%) & $0.53 \pm 0.71$ & $0.26 \pm 0.73$ & 0.03 \\
Pre & & & \\
Post & $62.2 \pm 14.8$ & $60.4 \pm 17.7$ & 0.54 \\
Follow-up & $10.4 \pm 10.7$ & $10.8 \pm 10.4$ & 0.82 \\
\hline
\end{tabular}

Abbreviations see in Tables 1,2.

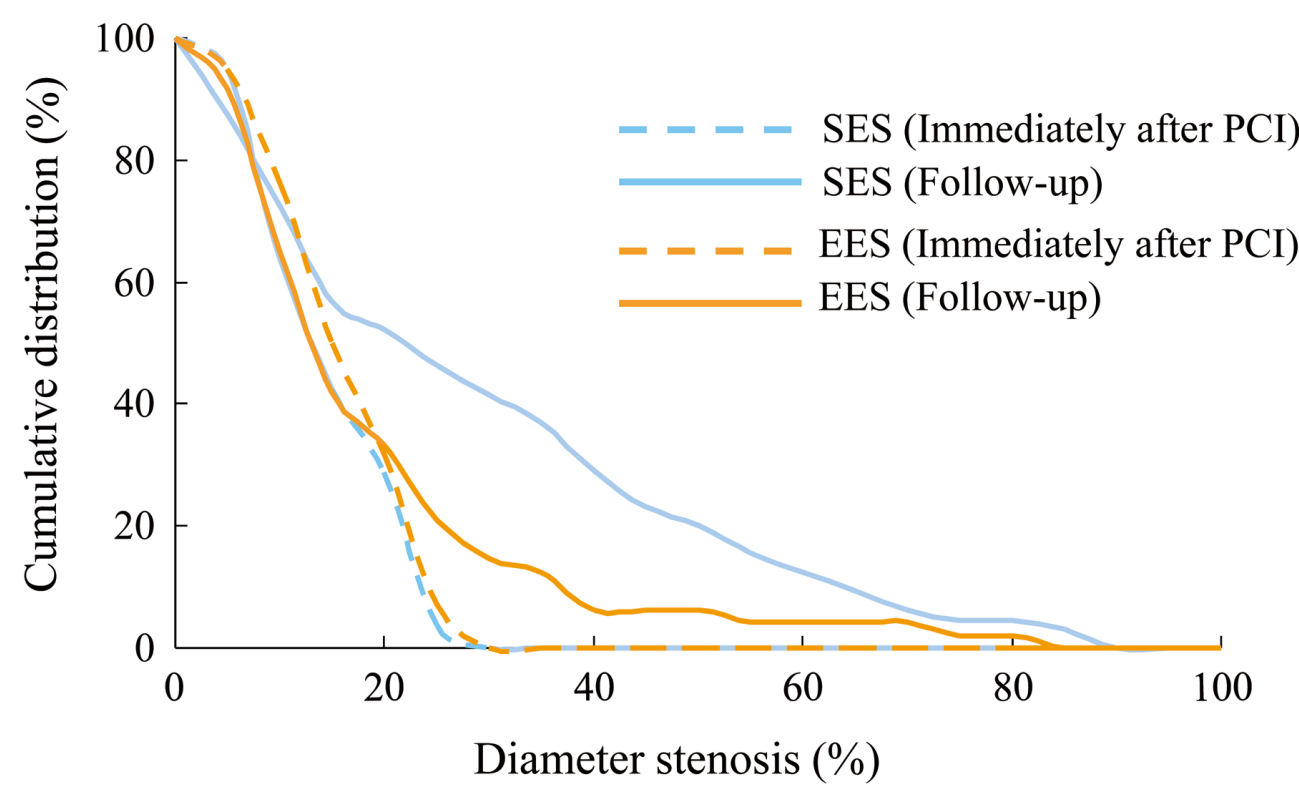

Figure. Cumulative distribution curves of diameter stenosis immediately after percutaneous coronary intervention (PCl) procedure and at follow-up angiography. Diameter stenosis after $\mathrm{PCI}$ procedure was similar between the 2 stent groups. Percent diameter stenosis at 8-month follow-up was significantly higher in the SES group than in the EES group $(P=0.0024)$. EES, everolimus-eluting stent; SES, sirolimus-eluting stent.

were entered into a logistic multivariable model in order to determine independent predictors. Differences were considered significant at $\mathrm{P}<0.05$. All statistical analyses were performed using SPSS (SPSS, Chicago, IL, USA).

\section{Results}

\section{Baseline Characteristics}

A total of 50 patients with 73 lesions were assigned to SES and 50 patients with 74 lesions to EES. All patients underwent successful PCI with the assigned stent implantation without in-hospital complications, including death or the necessity for additional surgical procedure. Table 1 shows the baseline characteristics in the SES and EES groups. No significant difference was detected in the lesion characteristics or QCA data (Table 2).
Complete 8-month follow-up coronary angiography data were obtained for 46 patients $(92.0 \%)$ with 66 stents $(90.4 \%)$ in the SES group and 47 patients (94.0\%) with 69 stents (93.2\%) in the EES group. All patients who did not undergo followup angiography did not have symptoms related to cardiac ischemia and all refused restudy angiography. Restenosis was seen in $21.2 \%$ of lesions within the SES group and in $8.7 \%$ of those within the EES group $(\mathrm{P}=0.041)$. Significant differences were seen in $\%$ diameter stenosis $(24.1 \pm 23.0 \%$ vs. $12.0 \pm 21.9 \%$, $\mathrm{P}=0.0024), \mathrm{MLD}(2.14 \pm 0.74 \mathrm{~mm}$ vs. $2.48 \pm 0.59 \mathrm{~mm}, \mathrm{P}=0.0040)$ and late lumen loss $(0.53 \pm 0.71 \mathrm{~mm}$ vs. $0.26 \pm 0.73 \mathrm{~mm}, \mathrm{P}=0.033)$ in the QCA data from the follow-up phase (Table 3, Figure). We performed a logistic regression analysis to determine predictive risks for restenosis after PCI. EES significantly prevented restenosis in the univariate logistic analysis (odds ratio $[\mathrm{OR}]$ 0.35; 95\% confidence interval [CI] 0.13-0.98; $\mathrm{P}=0.046$ ). 


\begin{tabular}{|c|c|c|c|c|}
\hline & \multicolumn{2}{|c|}{ Univariate } & \multicolumn{2}{|c|}{ Multivariate } \\
\hline & HR $(95 \% \mathrm{Cl})$ & $P$ value & $\mathrm{HR}(95 \% \mathrm{Cl})$ & $P$ value \\
\hline EES (vs. SES) & $0.35(1.13-0.98)$ & 0.046 & $0.20(0.05-0.78)$ & 0.022 \\
\hline Male & $0.79(0.28-2.23)$ & 0.65 & & \\
\hline Age & $1.02(0.97-1.07)$ & 0.51 & & \\
\hline Diabetes & $1.70(0.51-5.67)$ & 0.38 & & \\
\hline Hypertension & $1.23(0.40-3.84)$ & 0.71 & & \\
\hline Dyslipidemia & $1.42(0.43-4.72)$ & 0.56 & & \\
\hline ACC/AHA Type B2/C & $1.27(0.43-4.72)$ & 0.56 & & \\
\hline Minimum lumen diameter & $0.82(0.70-0.97)$ & 0.020 & $0.81(0.69-0.97)$ & 0.023 \\
\hline Lesion length & $1.04(0.95-1.13)$ & 0.40 & & \\
\hline Calcified lesion & $4.44(1.56-9.66)$ & 0.0052 & $2.24(0.63-8.01)$ & 0.11 \\
\hline Bifurcation lesion & $1.71(0.59-4.94)$ & 0.32 & & \\
\hline
\end{tabular}

$\mathrm{HR}$, hazard ratio; $\mathrm{Cl}$, confidence interval. Other abbreviations see in Tables 1,2.

Even after adjusting for other risk factors at baseline, EES remained an independent predictor of preventing restenosis after PCI (OR 0.20; 95\% CI 0.05-0.78; $\mathrm{P}=0.022$ ) (Table 4). MLD at baseline was also an independent predictor of restenosis in the follow-up period.

Clinical follow-up data during the year after PCI was obtained for all patients. The incidence of the composite endpoint including all-cause death, nonfatal myocardial infarction and TLR was $22.0 \%$ in the SES group and $10.0 \%$ in the EES group $(\mathrm{P}=0.10)$. There was no significant difference between the SES and EES groups in the rates of all-cause death and nonfatal myocardial infarction $(2.0 \%$ vs. $2.0 \%, \mathrm{P}>0.99$, and $4.0 \%$ vs. $4.0 \%, \mathrm{P}>0.99$, respectively). Implantation of EES was of borderline significance in TLR, because of stent restenosisinduced ischemia $(18.0 \%$ vs. $6.0 \%, \mathrm{P}=0.064)$. There was no event related to in-stent thrombosis in either group. The stenttreated vessel was not a culprit lesion in any patient who experienced acute myocardial infarction after stent implantation.

\section{Discussion}

We found that the use of EES was as safe as that of SES, but in addition, the EES significantly prevented restenosis in patients on maintenance HD compared with the SES. Recent studies have found that implantation of EES reduces the risk of restenosis and major adverse cardiovascular events, ${ }^{15-19}$ but until now, data on the EES concerning clinical outcomes after PCI in HD patients have been lacking. We have provided additional information on the safety and efficacy of the EES in HD patients who are at high risk of cardiac events.

PCI has been widely performed in HD patients with coronary artery disease, ${ }^{4,5}$ but these patients frequently have complex lesions, resulting in higher restenosis rates after PCI. ${ }^{21}$ Moreover, the atherosclerotic process and inflammation may affect progressive intimal hyperplasia after SES implantation. ${ }^{22-24}$ Thus, a higher restenosis rate remains a major clinical limitation in HD patients even in the era of first-generation DES. ${ }^{7-14}$ From these points of view, our findings might be of great significance.

In the meta-analysis by Stone et al, EES performed less well in patients with diabetes..$^{25}$ In the present study, however, there was no difference in the restenosis rate in the EES patients with and without diabetes (data not shown). However, some mechanisms can possibly explain why the EES reduced restenosis compared with the SES. Complex morphologies such as calcified lesions are frequently seen in HD patients, compared with non-HD patients, ${ }^{21,26}$ and in that regard the implantation of EES in calcified lesions is associated with favorable reduction of restenosis and repeat revascularization ${ }^{19}$ compared with previously reported stent studies. The drug itself, its release and the polymer of each DES also possibly affects the results. Severe inflammation, which is probably related to the polymer rather than the drug, is frequently seen with the Cypher ${ }^{\mathrm{TM}}$ stent compared with the Xience $\mathrm{V}^{\mathrm{TM}}$ stent. ${ }^{27}$ Furthermore, the Xience VTM stent, which was used as the EES in the present study, has a thinner strut (0.0032 inches) compared with that of the Cypher ${ }^{\mathrm{TM}}$ stent $(0.0055$ inches). It has been reported that the use of coronary stents with thinner struts significantly reduces restenosis after stent implantation. ${ }^{28}$ These mechanisms may be related to less arterial injury and less hypersensitivity reactions, resulting in prevention of restenosis. In addition, a study has suggested that more rapid endothelialization is seen after implantation of the EES compared with the SES and paclitaxel- eluting stent. ${ }^{18}$ Overall, the EES has beneficial effects as shown in our results.

In the present study, the rate of incidence of major adverse events was similar between the 2 groups. It has been reported that restenosis is associated with increased risk of death after $\mathrm{PCI},{ }^{29}$ so it is possible that preventing restenosis may improve clinical outcome. Furthermore, there are some reports of late complications, such as very-late stent thrombosis and latecatch up phenomenon, after SES implantation, although there are limited data on the EES in this context. Thus, we should collect more long-term data.

\section{Study Limitations}

First, the present trial was a single-center design. Because there were limited data from which we might obtain the magnitude of the effects, we did not perform a sample size calculation to justify the number of subjects enrolled. However, we enrolled $100 \mathrm{HD}$ patients in 5 months. In the situation, approximately 500 PCIs were performed each year. In addition, half of such patients undergo HD because the center has a large dialysis center. Thus, the number of enrolled patients during 5 months was not so high for this institution. Second, all patients were Japanese. A study has reported that Japanese have a better prognosis than subjects in other countries. ${ }^{30}$ Third, the rate of use of rotational atherectomy might be low, because we used intravascular ultrasound in PCI and rotational atherectomy was used for severe calcified lesions across which intravascular ultrasound could not cross. Fourth, we did not collect angiographic 8-month follow-up for all patients, although we 
did evaluate clinical follow-up data for all patients.

\section{Conclusions}

The present study demonstrated that HD patients have a markedly lower restenosis rate with clinical safety after implantation of the EES, compared with the SES. Implantation of the EES during PCI might be a good strategy for HD patients with ischemic heart disease.

\section{Acknowledgments}

This study was supported by a grant from the Aichi Kidney Foundation, Nagoya, Japan

\section{References}

1. Herzog CA, Ma JZ, Collins AJ. Poor long-term survival after acute myocardial infarction among patients on long-term dialysis. $N$ Eng J Med 1998; 339: 799-805.

2. Cheung AK, Sarnak MJ, Yan G, Dwyer JT, Heyka RJ, Rocco MV, et al; The Hemodialysis (HEMO) Study. Atherosclerotic cardiovascular disease risks in chronic hemodialysis patients. Kidney Int 2000; 58: $353-362$

3. Kumada Y, Aoyama T, Ishii H, Tanaka M, Kawamura Y, Takahashi $\mathrm{H}$, et al. Long-term outcome of percutaneous transluminal angioplasty in chronic haemodialysis patients with peripheral arterial disease. Nephrol Dial Transplant 2008; 23: 3996-4001.

4. Ting HH, Tahirkheil NK, Berger PB, McCarthy JT, Timimi FK, Mathew V, et al. Evaluation of long-term survival after successful percutaneous coronary intervention among patients with chronic renal failure. Am J Cardiol 2001; 87: 630-633.

5. Yasuda K, Kasuga H, Aoyama T, Takahashi H, Toriyama T, Kawade $\mathrm{Y}$, et al. Comparison of percutaneous coronary intervention with medication in the treatment of coronary artery disease in hemodialysis patients. J Am Soc Nephrol 2006; 17: 2322-2332.

6. Hemmelgarn BR, Ghali WA, Quan H, Brant R, Norris CM, Taub KJ, et al. Poor long-term survival after coronary angiography in patients with renal insufficiency. Am J Kidney Dis 2001; 37: 64-72.

7. Halkin A, Selzer F, Marroquin O, Laskey W, Detre K, Cohen H. Clinical outcomes following percutaneous coronary intervention with drug-eluting vs. bare-metal stents in dialysis patients. J Invasive Cardiol 2006; 18: 577-583.

8. Aoyama T, Ishii H, Toriyama T, Takahashi H, Kasuga H, Murakami $\mathrm{R}$, et al. Sirolimus-eluting stents versus bare metal stents for coronary intervention in Japanese patients with renal failure on hemodialysis. Circ J 2008; 72: 56-60.

9. Okada T, Hayashi Y, Toyofuku M, Imazu M, Otsuka M, Sakuma T, et al. One-year clinical outcomes of dialysis patients after implantation with sirolimus-eluting coronary stents. Circ J 2008; 72: 14301435 .

10. Nakazawa G, Tanabe K, Aoki J, Yamamoto H, Higashikuni Y, Onuma $\mathrm{Y}$, et al. Impact of renal insufficiency on clinical and angiographic outcomes following percutaneous coronary intervention with sirolimus-eluting stents. Catheter Cardiovasc Interv 2007; 69: 808 814.

11. Mori S, Yasuda S, Kataoka Y, Morii I, Kawamura A, Miyazaki S Significant association of coronary artery calcification in stent delivery route with restenosis after sirolimus-eluting stent implantation. Circ J 2009; 73: 1856-1863.

12. Nakamura M, Yokoi H, Hamazaki Y, Watarai M, Kijima M, Mitsudo $\mathrm{K}$; Cypher J-PMS Investigators. Impact of insulin-treated diabetes and hemodialysis on long-term clinical outcomes following sirolimuseluting stent deployment. Insights from a sub-study of the Cypher Stent Japan Post-Marketing Surveillance (Cypher J-PMS) Registry. Circ J 2010; 74: 2592-2597.

13. Otsuka Y, Ishikawa S, Inada T, Kanno H, Kyo E, Hayashi Y, et al. Comparison of haemodialysis patients and non-haemodialysis patients with respect to clinical characteristics and 3-year clinical outcomes after sirolimus-eluting stent implantation: Insights from the Japan multi-centre post-marketing surveillance registry. Eur Heart J 2011;
32: 829-837.

14. Natsuaki M, Furukawa Y, Morimoto T, Nakagawa Y, Akao M, Ono $\mathrm{K}$, et al. Impact of diabetes on cardiovascular outcomes in hemodialysis patients undergoing coronary revascularization. Circ J 2011; 75: $1616-1625$

15. Räber L, Jüni P, Nüesch E, Kalesan B, Wenaweser P, Moschovitis A, et al. Long-term comparison of everolimus-eluting and sirolimuseluting stents for coronary revascularization. J Am Coll Cardiol 2011; 57: $2143-2151$

16. Smits PC, Kedhi E, Royaards KJ, Joesoef KS, Wassing J, RademakerHavinga TA, et al. 2-Year follow-up of a randomized controlled trial of everolimus- and paclitaxel-eluting stents for coronary revascularization in daily practice: The COMPARE (comparison of the everolimus eluting XIENCE-V stent with the paclitaxel eluting TAXUS LIBERTÉ stent in all-comers: A randomized open label trial) trial. $J$ Am Coll Cardiol 2011; 58: 11-18.

17. Valenti R, Vergara R, Migliorini A, Parodi G, Buonamici P, Cerisano $\mathrm{G}$, et al. Comparison of everolimus-eluting stent with paclitaxel-eluting stent in long chronic total occlusions. Am J Cardiol 2011; 107: $1768-1771$.

18. Serruys PW, Ruygrok P, Neuzner J, Piek JJ, Seth A, Schofer JJ, et al. A randomised comparison of an everolimus-eluting coronary stent with a paclitaxel-eluting coronary stent: The SPIRIT II trial. EuroIntervention 2006; 2: 286-294.

19. Onuma Y, Tanimoto S, Ruygrok P, Neuzner J, Piek JJ, Seth A, et al. Efficacy of everolimus eluting stent implantation in patients with calcified coronary culprit lesions: Two-year angiographic and threeyear clinical results from the SPIRIT II study. Cathet Cardiovasc Interv 2010; 76: 634-642.

20. Ryan TJ, Bauman WB, Kennedy JW, Kereiakes DJ, King SB 3rd, McCallister BD, et al. Guidelines for percutaneous transluminal coronary angioplasty: A report of the American Heart Association/ American College of Cardiology Task Force on Assessment of Diagnostic and Therapeutics Cardiovascular Procedures (Committee on Percutaneous Transluminal Coronary Angioplasty). Circulation 1993; 88: 2987-3007.

21. Hase H, Nakamura M, Joki N, Tsunoda T, Nakamura R, Saijyo T, et al. Independent predictors of restenosis after percutaneous coronary revascularization in haemodialysis patients. Nephrol Dial Transplant 2001; 16: $2372-2377$

22. Ishii H, Kumada Y, Toriyama T, Aoyama T, Takahashi H, Amano $\mathrm{T}$, et al. Aortic valvular calcification predicts restenosis after implantation of drug-eluting stents in patients on chronic haemodialysis. Nephrol Dial Transplant 2009; 24: 1562-1567.

23. Ishii H, Toriyama T, Aoyama T, Takahashi H, Amano T, Hayashi $\mathrm{M}$, et al. Prognostic values of C-reactive protein levels on clinical outcome after implantation of sirolimus-eluting stents in patients on hemodialysis. Circ Cardiovasc Interv 2009; 2: 513-518.

24. Hao H, Ishibashi-Ueda H, Tsujimoto M, Ueda Y, Shite J, Gabbiani $\mathrm{G}$, et al. Drug-eluting stent: Importance of clinico-pathological correlations. Circ J 2011; 75: 1548-1558.

25. Stone GW, Kedhi E, Kereiakes DJ, Parise H, Fahy M, Serruys PW, et al. Differential clinical responses to everolimus-eluting and Paclitaxel-eluting coronary stents in patients with and without diabetes mellitus. Circulation 2011; 124: 893-900.

26. Jung HH, Kim SW, Han H. Inflammation, mineral metabolism and progressive coronary artery calcification in patients on haemodialysis. Nephrol Dial Transplant 2006; 21: 1915-1920.

27. Nakazawa G, Finn AV, Ladich E, Ribichini F, Coleman L, Kolodgie FD, et al. Drug-eluting stent safety: Findings from preclinical studies. Expert Rev Cardiovasc Ther 2008; 6: 1379-1391.

28. Kastrati A, Mehilli J, Dirschinger J, Dotzer F, Schühlen H, Neumann FJ, et al. Intracoronary stenting and angiographic results: Strut thickness effect on outcome (ISAR-STEREO) trial. Circulation 2001; 103: $2816-2821$.

29. Schühlen H, Kastrati A, Mehilli J, Hausleiter J, Pache J, Dirschinger $\mathrm{J}$, et al. Restenosis detected by routine angiographic follow-up and late mortality after coronary stent placement. Am Heart J 2004; 147: 317-322.

30. Bhatt DL, Eagle KA, Ohman EM, Hirsch AT, Goto S, Mahoney EM, et al. Comparative determinants of 4-year cardiovascular event rates in stable outpatients at risk of or with atherothrombosis. JAMA 2010; 304: $1350-1357$. 